\title{
Profiles in Paint: contrasting responses to a common artistic exercise by people with different
}

\section{dementias}

Charles R. Harrison, Amelia M. Carton, Emilie V. Brotherhood, Chris J. D. Hardy, Miriam H.

Cohen, Jason D. Warren, Sebastian J. Crutch, on behalf of the Created Out of Mind team

Created Out of Mind residency, The Hub, Wellcome Collection, London, UK

and

Dementia Research Centre, Department of Neurodegenerative Disease, UCL Institute of Neurology, University College London, UK

Correspondence details: c.harrison@ucl.ac.uk

\begin{abstract}
Paintings could offer insight into the varied experiences of people with different dementias. In this project, a single exercise - the painting of a group of objects in still-life - was used to capture artistic production in four artists with different diagnoses of dementia and four healthy artists. Whilst quantitative studies provide important insights into the neuroanatomical supports for artistic actions, autonomous art exercises may yield deeper understanding of the individual creative experience in the context of neurodegenerative disease.
\end{abstract}

Keywords: Visual arts, Dementias, Neuroscience, Interdisciplinary research 


\section{Introduction}

One of the first creative activities that people undertake, often with both relish and frustration, is the manipulation of figure and ground in two dimensions with paint on canvas (or related materials). This activity remains significant for many throughout their lives whilst for others the impulse subsides or lies dormant. Artists make many visual and sensual choices when they paint, but often begin by attempting the accurate representation of reality. For people with dementia the experience of reality can be variously altered, with conditions such as typical Alzheimer's disease (tAD), primary progressive aphasia (PPA), behavioural variant frontotemporal dementia (bvFTD) and posterior cortical atrophy (PCA) impacting differentially upon memory, language, behaviour, and perception.

An initial review of creativity and dementia (Palmiero et al, 2012) has recognised the complicated relationship between diagnosis and individual motivations for creative activity, whilst also proposing more controlled studies in this area. Other research (Mazzuchi et al, 2013) has recognised the value of artistic creativity and the possible affects of impairment on style and content in artmaking. Consideration of artistic change in the context of dementia has relied almost solely upon retrospective review of individual bodies of work by well-known artists (Crutch, Isaacs \& Rossor, 2001; Espinel, 1996; Storr R, 1995). One exception is the prospective study aiming to characterize dementia-induced changes in visual art production across individuals with diagnoses of Alzheimer's disease, frontotemporal dementia and semantic dementia alongside healthy controls (Rankin et al, 2007). Whilst the study shows semi-quantitative distinctions between the different diagnostic groups and provides meaningful insight into the neuroanatomical substrates of artistic production, the clinical setting and simplified pragmatics of testing may leave little room for individual artistic identity to flourish. A further small body of work has sought to identify syndromic signals of art perception and emotional comprehension at group level using structured visual art stimulus sets (Cohen et al, 2016). 
Whilst different forms of dementia result in characteristic profiles of cognitive impairment, the assumption that dementia leads also to artistic or stylistic decline (as if the intentions of the artist or the qualitative assessment of art were fixed) is problematic. The value of artistic practice may inhere in the self-representation of reality at that moment - whatever that reality may be - even if the artist feels that her abilities and tools are blunted. We designed this project to provide a framework within which rich artistic decisions could be made, whilst holding stimulus and materials constant. The chief aims of the project were to gain deeper insight into the experience of different dementias and to highlight the creative capacity which remains in the diseased brain.

\section{Methods}

Participants were four people with dementia, each meeting diagnostic criteria for a different dementia (bvFTD (Rascovsky, Hodges, Knopman D, et al. 2011), PPA [unclassifiable] (GornoTempini, Hillis, Weintraub, et al. 2011), AD (Dubois, Feldman, Jacova, et al. 2014) \& PCA (Crutch, Schott, Rabinovici, et al. 2017)) and four healthy participants; see demographic and neuropsychological information in Table 1). All participants demonstrated a current or recent interest in art-making (see Table 1).

Procedures: Each participant was visited at their home by an artist $(\mathrm{CH})$ and psychologist $(\mathrm{AC}, \mathrm{EB}$ or $\mathrm{CJH}$ ) and presented with a grey box containing the same 12 objects (chosen to present a range of functional and perceptual challenges; golden delicious apple, granadilla fruit, coaster, striped coffee mug, tupperware pot filled with 6 digestive biscuits, glass bottle, newspaper, clock, battery, peeler, pen, sunflower; see Figure 1). Participants also received identical materials (grey square canvas, brushes, coloured acrylic paints). Participants were asked to open the box, identify and describe each object alongside the researchers, and were then left to arrange the objects however they wished and complete a painting of their arrangement in their own space and time. Participants were advised that their paintings should take between 1-10 hours. 
Web survey: An online survey about the resulting artworks was constructed and completed by a group of 19 international neurologists, psychologists, and allied health professionals with extensive experience of rarer forms of dementia (mean [sd] years' experience since primary medical or research qualification $=17.9[10.1]$ years). Participants were requested to indicate which four of the eight paintings (pseudorandomly rearranged from Figure 2) may have been made by someone living with a dementia. Subsequently the four paintings made by people living with a dementia (Figures 2A-D only) were re-presented, and participants were requested to indicate which painting may have been made by the artist living with PCA, bvFTD, PPA and typical AD respectively.

\section{Artwork}

The paintings created by the artists living with and without dementia are presented in Figure 2, with previous productions by the artists with dementia shown for context in Figure 3.

The painting with the most prominent disruption to volumetric representation was executed by the artist with PCA (see Figure 2A). Significant difficulties were experienced with the perception of the objects, with many subject to profound distortion (consistent with recognised disturbances of visuoperceptual processing and figure-ground discrimination (Lehmann et al, 2011)). The glass bottle becomes a series of flashes of white, the clock and striped cup a mass of directional movements. The rendition of the fruit and sunflower has remained largely accurate - perhaps their circular forms best suiting the artist's adopted technique of stippling an area and then rotating the canvas (see Figure 3A). The artist had difficulty representing the spatial relationships between objects (consistent with visuospatial processing deficits) and comprehending the multiple objects as a single composed arrangement was impossible (likely reflecting simultanagnosia or reduced effective field of vision); instead each object had to be approached and assessed individually. Some of the objects, such as the sunflower and the grey box have been subject to colour distortion, and the 
orange/green patterning along the right-hand side of the canvas is a depiction of colour after-images reportedly experienced during the painting process (Chan, Crutch \& Warrington, 2001). There are 3 batteries painted as the artist saw the single battery in triplicate (suggestive of diplopia). The artist commented that he enjoyed creating texture or "bumpy bits", highlighting the multi-faceted sensual qualities of art-making.

The work made by the artist with bvFTD (see Figure 2B) contrasts bluntly with the PCA and other artists' compliance with the format of the exercise, possibly consistent with reported reduced adherence to social norms and conventions in bvFTD. The depiction of the St George's flag represents the artist's stated wish to express something of their identity through the painting; although the instructions encouraged the exercise to be used as a way to tell a story about the individual, the unrestrained and idiosyncratic nature of the painting brings to mind reports of increased or released creativity in bvFTD (Miller et al, 1998). Additionally, the disregard for all the objects other than the clock may reflect perseveration of the horological theme of many previous works (see Figure 3B). Inflexibility was also evident in the artist's assertion that his drawings must be perfect or be destroyed, and in the numbers on the clock-face, which have been intentionally rearranged and overpainted a number of times.

Similarly revealing is the artwork by the artist with PPA (see Figures $2 \mathrm{C}$ and $3 \mathrm{C}$ ). The artist has chosen to separate what would usually be thought of as the common still-life objects and depict them within a fictitious canvas, within the frame of the actual canvas. Other 'less common' objects can still be seen, but around the peripheries and in the background of the composition, possibly reflecting the linguistic frequency of items. This artist has little trouble perceiving the objects, and has conceptually grasped and run with the exercise, but the flatness and lack of details may reflect a loss of visual syntax and object knowledge. The manufactured structure linking the objects and the apparent lack of detail could be interpreted as a loss of visual syntax / object knowledge in this 
diagnosis or contrastingly these aspects could be ascribed to individual creative skill \& decision making.

The striking compositional similarity between the artist with typical AD (Figure 2D) and the control painting with the green background (Figure $2 \mathrm{H}$ ) is entirely coincidental but nevertheless effective in drawing out some of the difficulties the artist may experience. The painting on the whole seems less finished, the battery is not in the clock, the sunflower is missing, as are the shadows. The rendition of most objects is as articulate and skilfully handled as in any of the other paintings, although the structure and depiction of the bottle - arguably the most perceptually difficult object owing to its transparency - is challenging (consistent with subtly disordered visuoperceptual processing, and at odds with previous work [Figure 3D]). Otherwise the exercise has evidently been clearly understood; interpretations about this painting seem to be of a more atmospheric nature - the feeling that something is missing but you can't quiet put your finger on it.

Each of the paintings by an artist with dementia seems to have a match in the control set. Where one control painting (2E) has separated each of the objects out in an aerial view, similar to the painting by the artist with PCA (2A), another control painting (2F) is supremely rigid and meticulous, bearing relationships to the painting by the artist with bvFTD (2B). Control painting $2 \mathrm{G}$ also seems to resemble the work by the artist with PPA (2C) in the choices of colour and structuring of the canvas. This opportunity for comparison between work made by those with and without dementia, and the many different interpretations of the paintings by viewers, bears witness to the capacity of art making to embody a range of individual perspectives.

The dementia expert survey results are shown in Figure 4. The paintings created by artists with PCA, bvFTD and PPA (2A-C) were identified by the majority of participants, but also control painting $2 \mathrm{E}$, which was considered much more likely to have been made by someone with dementia 
than the work by the artist with tAD (2D). The majority of participants correctly attributed paintings to the artists with PCA (95\%) and bvFTD (84\%), but attributions were largely switched for the artists with PPA (21\% correct; 79\% attributed the PPA artist's work to someone with tAD) and tAD (16\% correct; $63 \%$ attributed the tAD artist's work to someone with PPA).

\section{Comment}

The paintings produced in this project highlight the broad range of effects of different dementias. As well as displaying information about the impaired visual brain and altered imaginative behaviours, this exercise provides a dramatic snapshot of the latent creative abilities of people with dementia. Creativity in the context of dementia is an under-examined topic and traditional art making activities such as painting offer only a narrow window into a subject with many possible dimensions. It is unlikely that creativity has a fixed relationship to diagnostic categories, so interpretations of artistic work will remain ambiguous. Comparison of the paintings in this project may impact and inform our understanding of the distributed brain networks that are likely to mediate creativity in the healthy brain and although there could be further discussion about which brain mechanisms add the most value to creative output; the artworks here make a compelling case that the most valuable renditions of artistic experience are recorded by the person themselves, in the act of creation.

\section{Consent}

All participants provided written consent to participate and share the paintings produced as part of this project. At the time of writing the manuscript, all participants were re-consented specifically regarding consent to publication. This was possible for all but one participant who had endured significant unrelated illness, whose partner gave verbal consent. 


\section{References}

Chan D, Crutch SJ, Warrington EK. (2001) A disorder of colour perception associated with abnormal colour after-images: a defect of the primary visual cortex. J Neurol Neurosurg Psychiatry, 71:515-7.

Cohen MH, Carton AM, Hardy CJ, Golden HL, Clark CN, Fletcher PD, Jaisin K, Marshall CR, Henley SM, Rohrer JD, Crutch SJ, Warren JD. (2016) Processing emotion from abstract art in frontotemporal lobar degeneration. Neuropsychologia, 81:245-54.

Crutch SJ, Isaacs R, Rossor MN. (2001) Some workmen can blame their tools: artistic change in an individual with Alzheimer's disease. Lancet, 357:2129-33.

Crutch SJ, Schott JM, Rabinovici GD, Murray M, Snowden JS, van der Flier WM ... Dickerson BC. (2017) Consensus classification of posterior cortical atrophy. Alzheimer's and Dementia; doi:0.1016/j.jalz.2017.01.014.

Dubois B, Feldman HH, Jacova C, Hampel H, Molinuevo JL, Blennow K, ... DeKosky ST. (2014) Advancing research diagnostic criteria for Alzheimer's disease: the IWG-2 criteria. Lancet Neurology, 13:614-29.

Espinel CH. (1996) De Kooning's late colours and forms: dementia, creativity, and the healing power of art. Lancet 347, 1096-98.

Gorno-Tempini ML, Hillis AE, Weintraub S, Kertesz A, Mendez M, Cappa SF, ... Ogar JM. (2011) Classification of primary progressive aphasia and its variants. Neurology, 76:1006-14.

Lehmann M, Barnes J, Ridgway GR, Wattam-Bell J, Warrington EK, Fox NC, Crutch SJ. (2011) Basic visual function and cortical thickness patterns in posterior cortical atrophy. Cerebral Cortex, 21:2122-32.

Mazzucchi A, Sinforiani E, Boller F. (2013) Artistic creativity, artistic production, and ageing. Prog Brain Res, 204: 45-69

Miller BL, Cummings J, Mishkin F, Boone K, Prince F, Ponton M, Cotman C. (1998) Emergence of artistic talent in frontotemporal dementia. Neurology, 51:978-82. 
Palmiero M, Di Giacomo D, Passafiume D. (2012). Creativity and dementia: A review. Cogn Process, 13(3), 193-209

Rankin KP, Liu AA, Howard S, Slama H, Hou CE, Shuster K, Miller BL. (2007) A case-controlled study of altered visual art production in Alzheimer's and FTLD. Cogn Behav Neurol, 20:48-61. Rascovsky K, Hodges JR, Knopman D, Mendez MF, Kramer JH, Neuhaus J, ... van Swieten JC. (2011) Sensitivity of revised diagnostic criteria for the behavioural variant of frontotemporal dementia. Brain, 134:2456-77.

Storr R. At last light. In: Jenkins J, Engberg S, eds. (1995) Willem de Kooning: the late paintings, the 1980s. Minneapolis: Wallace Carlson, 39-80. 

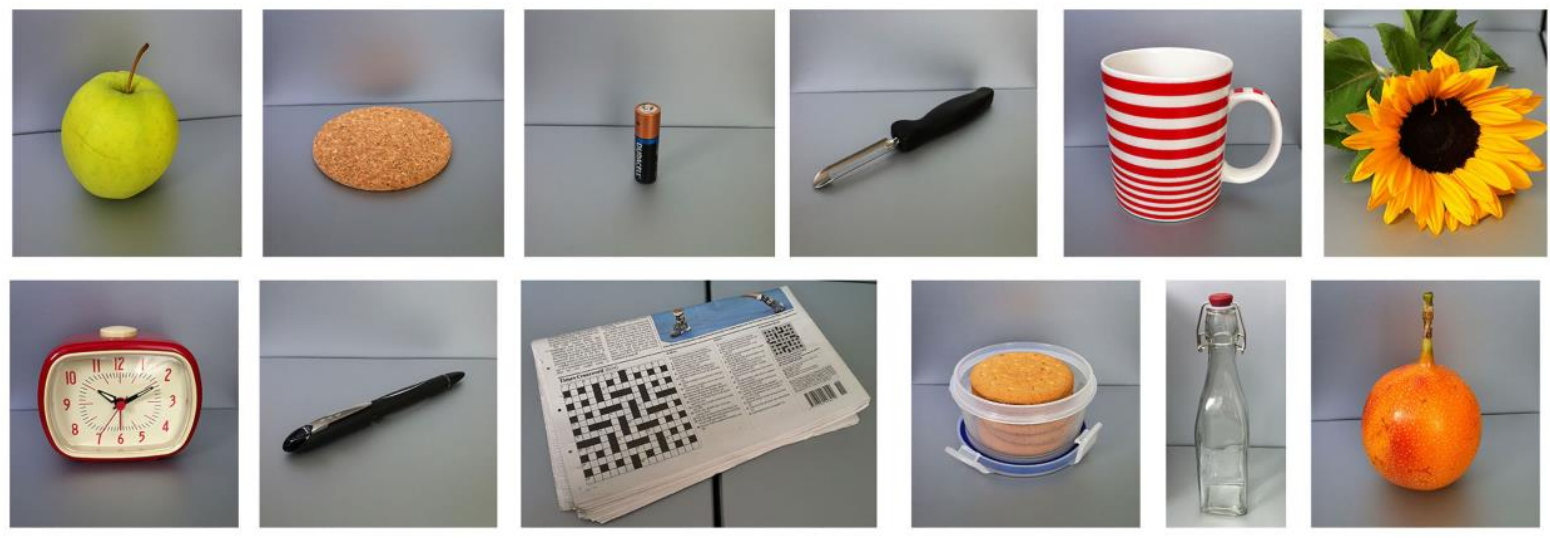

Figure 1. The twelve objects presented to each participating artist.

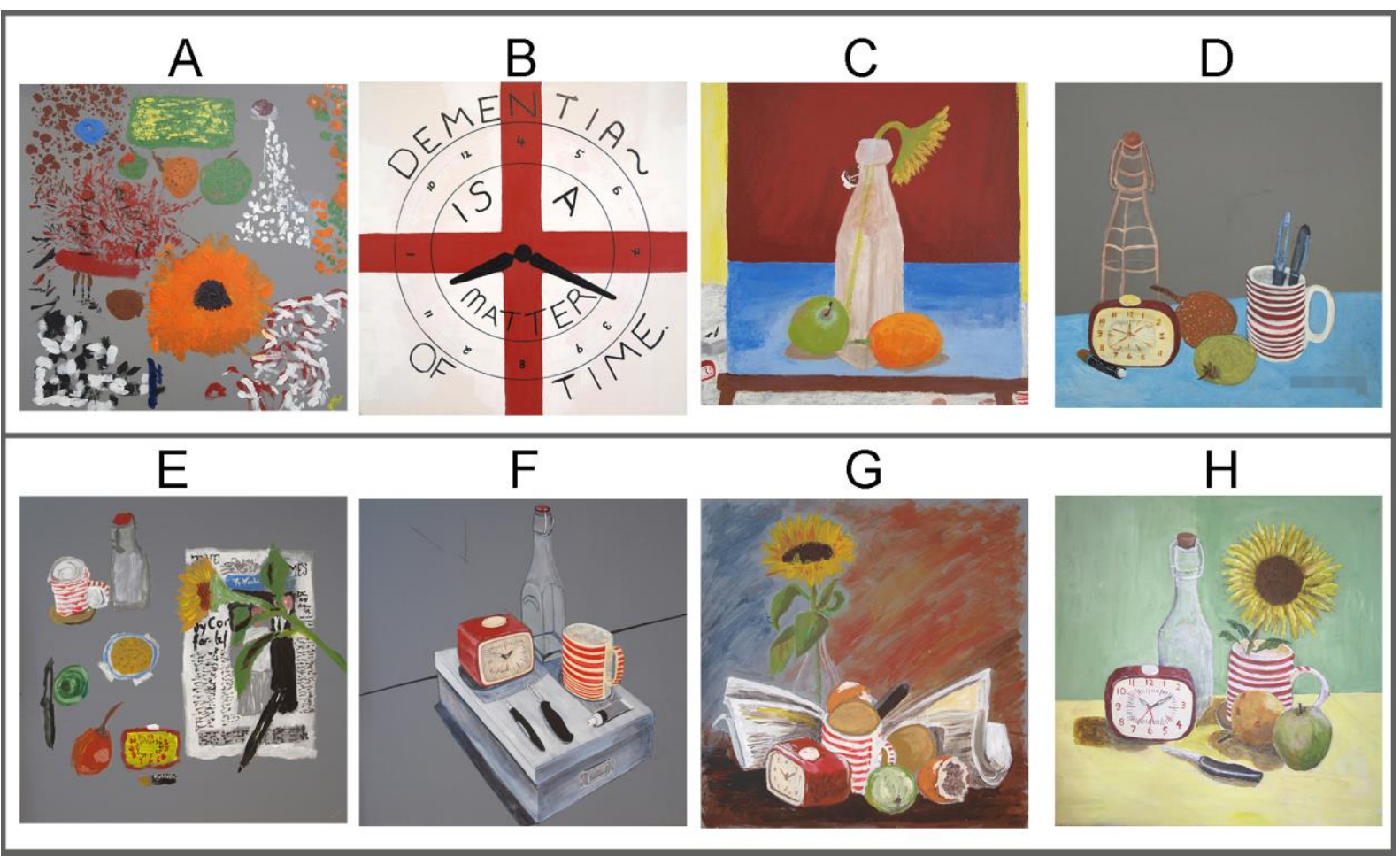

Figure 2. The paintings made by artist living with ( $A-D ; A=P C A, B=b v F T D, C=P P A, D=t A D)$ and without dementia $(\mathrm{E}-\mathrm{H})$. 


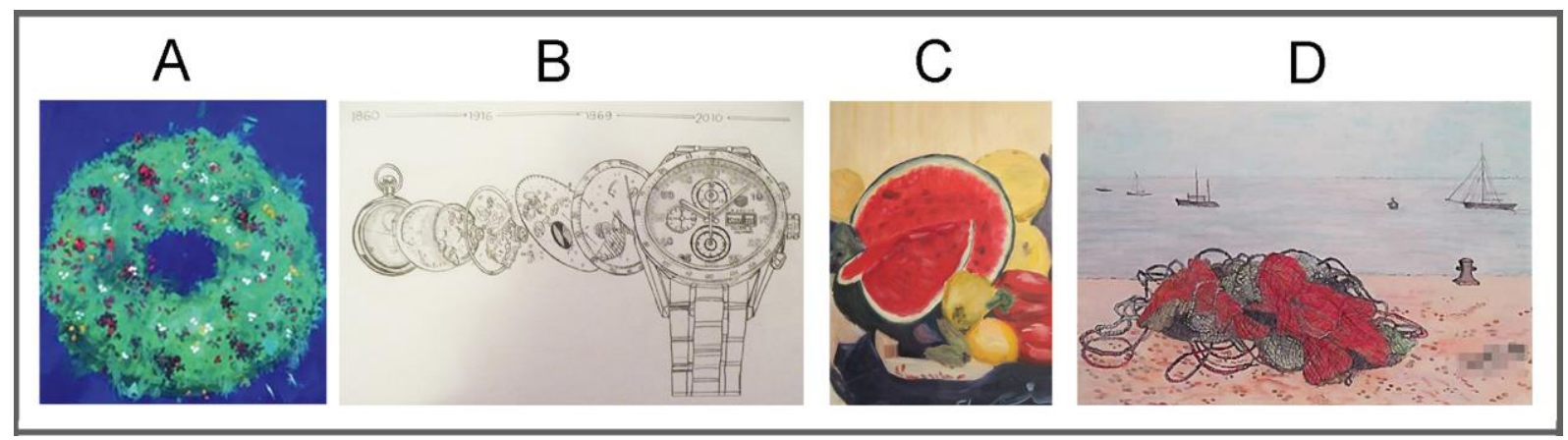

Figure 3. Previous artwork created by the artists living with dementia $(A=P C A, B=b v F T D, C=P P A$,

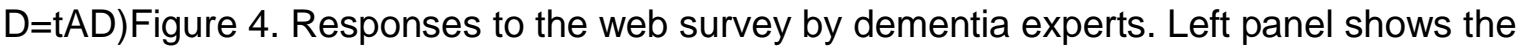
percentage of survey participants who attributed each painting to an artist living with dementia. Right panel shows the percentage of survey participants who attributed each of paintings 2A-D specifically to artists living with PCA, bvFTD, PPA or tAD. Hatched lines indicate correct attributions.
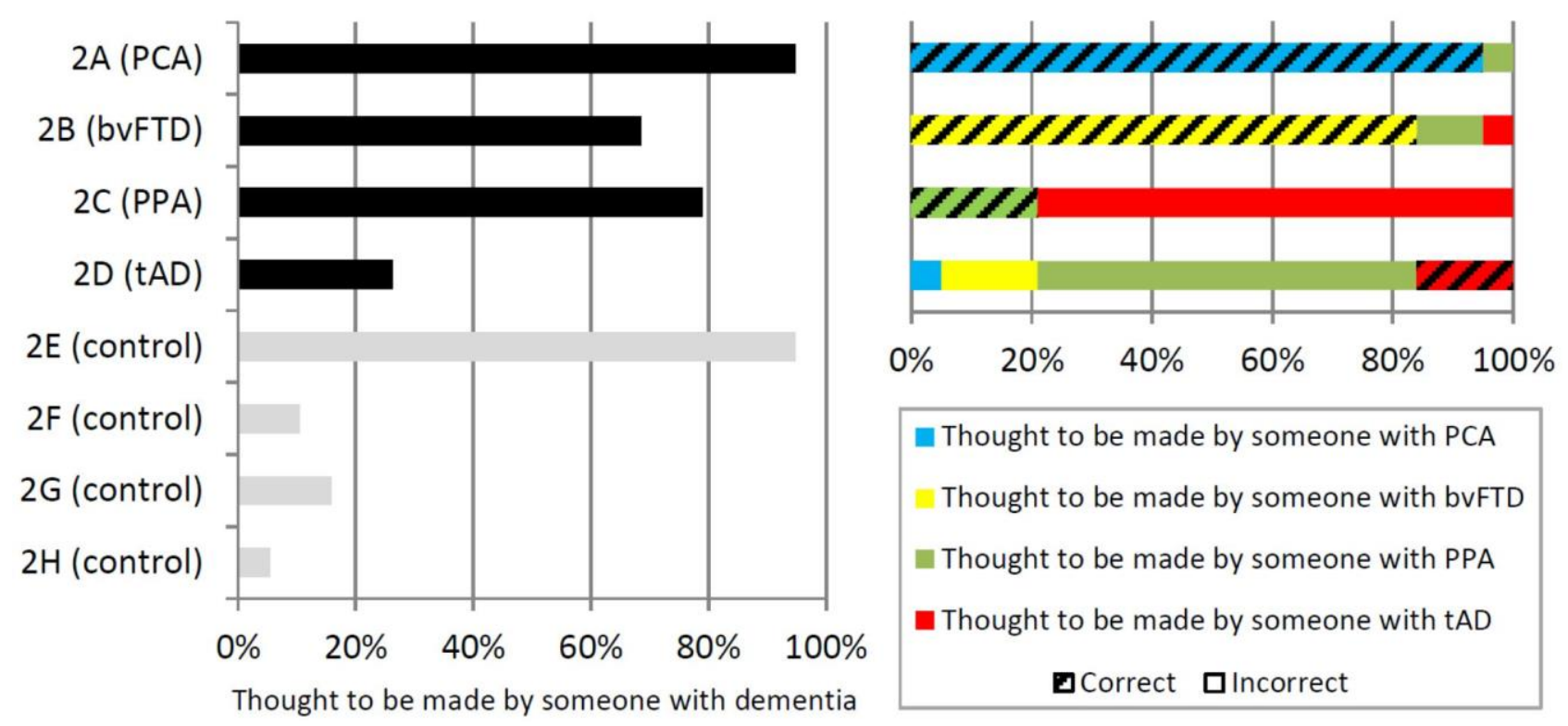

Thought to be made by someone with PCA

Thought to be made by someone with bvFTD

Thought to be made by someone with PPA

- Thought to be made by someone with tAD

घCorrect $\boldsymbol{\square}$ Incorrect

Figure 4. Responses to the web survey by dementia experts. Left panel shows the percentage of survey participants who attributed each painting to an artist living with dementia. Right panel shows the percentage of survey participants who attributed each of paintings $2 A-D$ specifically to artists living with PCA, bvFTD, PPA or tAD. Hatched lines indicate correct attributions. 
Table 1. Participant characteristics, artistic background and interests, and neuropsychological assessment results.

\begin{tabular}{|c|c|c|c|c|c|c|c|c|}
\hline & PCA $^{A}$ & bvFTD $^{\mathrm{B}}$ & PPA $^{\mathrm{C}}$ & $t^{A} D^{D}$ & Control $1^{\mathrm{E}}$ & Control $2^{\mathrm{F}}$ & Control $3^{G}$ & Control $4^{\mathrm{H}}$ \\
\hline Age (years) & 58 & 55 & 72 & 76 & 68 & 70 & 84 & 76 \\
\hline Gender & $\mathrm{M}$ & $\mathrm{M}$ & $\mathrm{M}$ & $\mathrm{F}$ & $\mathrm{M}$ & $\mathrm{M}$ & $\mathrm{F}$ & $\mathrm{M}$ \\
\hline Symptom Duration (years) & 5 & 15 & 6 & 5 & - & - & - & - \\
\hline \multicolumn{9}{|l|}{ Artistic background } \\
\hline Artistic training & O-Level & \begin{tabular}{|l|} 
Leisure \\
Class
\end{tabular} & $\begin{array}{l}\text { Leisure } \\
\text { Class }\end{array}$ & $\begin{array}{l}\text { Leisure } \\
\text { Class }\end{array}$ & $\mathrm{N} / \mathrm{A}$ & $\begin{array}{l}\text { Architecture } \\
\text { College }\end{array}$ & Art School & Leisure Class \\
\hline Usual medium & $\begin{array}{l}\text { Pencil } \\
\text { Drawing }\end{array}$ & Oil Paint & $\begin{array}{l}\text { Acrylics, } \\
\text { Watercolour }\end{array}$ & Acrylic, Oils & $\begin{array}{l}\text { Collage, } \\
\text { Photography }\end{array}$ & $\begin{array}{l}\text { Graphic } \\
\text { Drawing }\end{array}$ & $\begin{array}{l}\text { Watercolour, } \\
\text { Pen \& Ink }\end{array}$ & $\begin{array}{l}\text { Acrylics, } \\
\text { Watercolour }\end{array}$ \\
\hline Description of own work & $\begin{array}{l}\text { Abstract, } \\
\text { Semi-rep }\end{array}$ & Rep & $\begin{array}{l}\text { Abstract \& } \\
\text { Rep }\end{array}$ & Rep & Abstract & $\begin{array}{l}\text { Abstract, } \\
\text { Rep }\end{array}$ & Rep & Rep \\
\hline Currently producing art regularly? & $\mathrm{Y}$ & $\mathrm{Y}$ & $\mathrm{Y}$ & $\mathrm{N}$ & $\mathrm{Y}$ & $\mathrm{N}$ & $\mathrm{Y}$ & $\mathrm{Y}$ \\
\hline Frequency of art making & Monthly & Weekly & Weekly & $\mathrm{N} / \mathrm{A}$ & Daily & $\mathrm{N} / \mathrm{A}$ & Monthly & Monthly \\
\hline Art making environment & Taught & Home & Taught & $\mathrm{N} / \mathrm{A}$ & Home & Work & Home & $\begin{array}{l}\text { Taught \& } \\
\text { Home }\end{array}$ \\
\hline Viewing art (times per year) & $\mathrm{N} / \mathrm{A}$ & $1-6$ & $\mathrm{~N} / \mathrm{A}$ & $\mathrm{N} / \mathrm{A}$ & $>6$ & $1-6$ & $1-6$ & $1-6$ \\
\hline Kind of artwork most enjoyed & $\begin{array}{l}\text { Banksy, } \\
\text { Turner }\end{array}$ & Matisse & $\begin{array}{l}\text { Colourful, } \\
\text { Aboriginal }\end{array}$ & $\mathrm{N} / \mathrm{A}$ & $\begin{array}{l}\text { Modern, } \\
\text { Pointillism, } \\
\text { Naive }\end{array}$ & All forms & $\begin{array}{l}\text { Modern, } \\
\text { Traditional }\end{array}$ & Impressionist \\
\hline \multicolumn{9}{|l|}{ Neuropsychological assessment } \\
\hline $\mathrm{VIO}^{1}$ & 75-90th & $<5^{\text {th }}$ & $<5^{\text {th }}$ & $<5^{\text {th }}$ & - & - & - & - \\
\hline $\mathrm{PIQ}^{1}$ & $10-25^{\text {th }}$ & $10-25^{\text {th }}$ & $>95^{\text {th }}$ & $50-75^{\text {th }}$ & - & - & - & - \\
\hline Verbal memory ${ }^{2}$ & $10-25^{\text {th }}$ & $5-10^{\text {th }}$ & $10^{\text {th }}$ & $<5^{\text {th }}$ & - & - & - & - \\
\hline Visual memory ${ }^{3}$ & $5^{\text {th }}$ & $25-50^{\text {th }}$ & $95^{\text {th }}$ & $50-75^{\text {th } *}$ & - & - & - & - \\
\hline Language $^{4}$ & $10-25^{\text {th }}$ & $10-25^{\text {th }}$ & $<5^{\text {th }}$ & $<5^{\text {th }}$ & - & - & - & - \\
\hline Visuoperceptual $^{5}$ & $<5^{\text {th }}$ & $50-75^{\text {th }}$ & $50-75^{\text {th }}$ & $50-75^{\text {th }}$ & - & - & - & - \\
\hline Visuospatial $^{6}$ & $<5^{\text {th }}$ & - & - & $<5^{\text {th }}$ & - & - & - & - \\
\hline Processing speed ${ }^{7}$ & $<5^{\text {th }}$ & $10-25^{\text {th }}$ & $>90^{\text {th }}$ & $<10^{\text {th }}$ & - & - & - & - \\
\hline Executive function $^{8}$ & $<5^{\text {th }}$ & $>5^{\text {th }}$ & $>90^{\text {th }}$ & $<5^{\text {th }}$ & - & - & - & - \\
\hline
\end{tabular}

A-HReferring to individual artworks in Figure 2. ${ }^{1}$ Wechsler Abbreviated Scale of Intelligence (WASI): PCA, bvFTD \& PPA; Wechsler Adult Intelligence Scale-III (WAISIII): tAD. ${ }^{2}$ WMS-III Auditory Delayed: PCA; Recognition Memory Test (RMT) words: bvFTD, PPA \& tAD. ${ }^{3}$ WMS-III Visual Delayed: PCA; RMT faces: bvFTD, PPA \& tAD. ${ }^{4}$ Graded Naming Test (GNT). ${ }^{5}$ Visual Object and Space Perception (VOSP) battery Object Decision test: PCA, bvFTD \& PPA; VOSP Fragmented Letters test: tAD. ${ }^{6}$ VOSP Cube Analysis test. ${ }^{7}$ Trails A. ${ }^{8}$ Trails B (Tombaugh et al., 2003 norms). Rep=Representational art. 
